Gicht

\title{
Zu viel Harnsäure macht die Gefäße steif
}

\section{Gicht ist auch eine internistische Erkrankung. Denn Gicht schädigt nicht nur die Gelenke. Hohe Harnsäurewerte machen auch die Gefäße steif.}

Chronische Entzündung und Radikalbildung sind die Mechanismen der Gefäßschädigung bei Gicht. „Die Harnsäure als abgelagertes Kristall vermittelt über das Inflammasom eine Entzündung", so Dr. Anne-Kathrin Tausche, Rheumatologin an der TU Dresden. Dies erfolge vor allem bei der Phagozytose der Kristalle. Zum Zweiten ist bei der Harnsäurebildung die Xanthinoxidase aktiv. Ein Nebeneffekt: Es werden vermehrt Radikale gebildet, das führt zu einer Verminderung von Stickoxid (NO) und letztlich zu einer Gefäßkonstriktion. Dass eine Harnsäuresenkung positive Effekte auf die Gefäße haben kann, ist somit plausibel.
Tausche präsentierte hierzu Daten einer eigenen, kleinen Studie.

Dazu wurden Patienten mit schwerer Gicht, also alle mit Tophi und Anfällen in der Anamnese in zwei Gruppen aufgeteilt: Acht Patienten erhielten ein Jahr lang Febuxostat (Adenuric $^{\circledR}$ ), neun Patienten Allopurinol. Die ersten acht Wochen erfolgten mit zusätzlicher Anfallsprophylaxe. Der Harnsäurewert im Serum wurde in beiden Gruppen auf den Zielwert von unter $6 \mathrm{mg} / \mathrm{dl}$ gesenkt, und zwar mit im Mittel $460 \mathrm{mg}$ Allopurinol oder 90 mg Febuxostat. Ebenfalls in beiden Gruppen kam es zu einer Abnahme der Tophusvolumina um
$60 \%$. Eine signifikante Reduktion von TNFa und der Aktivität der NADPHOxidase - ein Marker für oxidativen Stress - gab es nur in der Febuxostat-Gruppe. Unterschiede zwischen den beiden Gruppen gab es ebenso bei der Gefäßfunktion. Diese wurde nur unter Febuxostat stabilisiert (Rheumatol Int 2014; 34: 101).

Dr. Michael Hubert

rheuma plus 2014 · 13:9

DOI 10.1007/s12688-014-0004-0

Online publiziert: 14. November 2014

○ Springer-Verlag Wien 2014
Quelle:

Satellitensymposium "Gicht als Symptomatische Hyperurikämie und Systemerkrankung", beim Kongress der Deutschen

Gesellschaft für Rheumatologie, 18. Sept. 2014 in Düsseldorf, Veranstalter:Berlin-Chemie

\section{Hier steht eine Anzeige.}

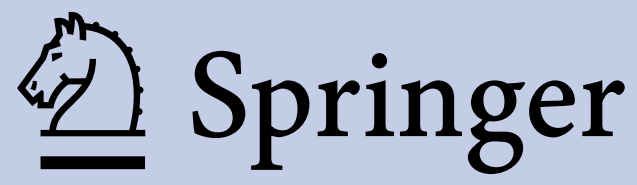

